\title{
WELDING WORK ORGANISATION IN SERIAL PRODUCTION
}

\author{
Gunars Verdins ${ }^{1}$, Kristine Elere ${ }^{2}$ \\ ${ }^{1}$ Latvia University of Life Sciences and Technologies, Latvia; ${ }^{2}$ Bucher Municipal Ltd, Latvia \\ gunars.verdins@1lu.lv, kristine.elere@inbox.lv
}

\begin{abstract}
The paper analyzes the course of welding work in conditions when products of different sizes, shapes and complexity are made in small batches. Research has been carried out to find the individual professional skills and abilities of welders in manufacturing parts with the MAG technology. Video recordings of the production process of various standard parts were recorded and analyzed. The aim is to find the possibilities to increase the production productivity by increasing the production intensity. The possibility to increase the productivity has been tested, taking into account the skills and abilities of welders in performing certain elements of the welding technology and rational use of the working time. To determine the professional skills and abilities of welders, a test is used, the task of which is to find the skills of each individual in forming seams, welding, performing auxiliary work related to welding and ensuring the quality of welds. The test results are compiled and used to create standard part manufacturing modes. The results of the observations were used to determine the time capacity of the welding work elements and to model the course of welding work. The test results show that the abilities of welders to produce the product are very different. The fastest welder in the test group takes twice as much time to weld a part as the slowest. The amount of wasted time in some cases is $30 \%$ of the product's manufacturing time. For welding long seams, it is desirable to assign welders with good skills to form the seams. Sewage treatment should be entrusted to less qualified personnel or machinery. By modelling the welding process, it has been found that by properly organizing the production, the work intensity for the tested contingent can be increased by $1 \ldots 8 \%$.
\end{abstract}

Keywords: welding work management, testing, time recording, rationing.

\section{Introduction}

One of the most effective technological solutions for producing three-dimensional parts and hull products in agriculture, communal vehicle manufacturing and specialized machine production companies with serial production is laser cutting flat pattern parts, folding them with bending press and welding with MAG or MIG technology. Resulting part quality and production time is greatly affected by organization of work and management. Required time for the welding process can be analysed with several methods. Inspecting and measuring welding work with stopwatch, it is possible to determine and estimate the required welding time, process core elements, maintenance and other time values required to perform current welding work [1]. Proper organization of welding work allows ensure rational use of labour, the required product quality and productivity. Productivity depends on the rational use of the working time, work intensity and technological provision of production [2-5]. Companies with a large volume of welding work and series production usually have a welding work plan coordinator, who is responsible for identifying the scope and specifics of work to be performed in a certain period of time. The input data are technical drawings and production requests. From these data, the planning manager creates a production order for each product and records the data in an information system, such as SAP [6]. The work plans developed in the SAP system show a description of individual operations and the sequence of execution. The production order and assembly drawings are sent to the welding foreman, whose task is to add the coordinates of the technical means and select the welding contractor. The qualification, work experience, skills and abilities of welders are the main factors that determine the quality of welding work and the time spent. To determine the skills and abilities of welders generally accepted tests based on the recommendations of the REF are used [7] or already tested principles [8]. The professional skills of a welder can be judged by his observation during working hours, such as video surveillance, which makes it possible to determine precisely the duration of all elements of the use of the working time. The time norm $N$ is determined by the formula: $N=M H+M N+M Z+M P+M E$. The basic time in $M H$ welding is summed from the seam formation time MH1 and the weld time $M H 2$. The welding time $M H 1$ and joint length data allow calculate the joint formation speed. The time taken by the welder to weld $M H 2$ makes it possible to estimate it in the basic time. The auxiliary time $M N$ inevitably related to the basic time is summed from the part moving time $M N 1$, the time for fixing parts $M N 2$, the time for changing the working position $M N 3$, the time for performing quality assessment activities $M N 4$, the time for starting work $M N 4$, the time for starting work $M N 5$, the part processing time $M N 6$, the welding surface $M N 7$ service time $M N 8$. The downtime of the welding process $M Z 1$, the time for physiological needs $M P$ and the time for rest $M E$ are regulated by labour legislation and do not 
depend on the qualification of the welder. Based on the results of the tests, it is possible to determine the possibilities of each individual to perform specific actions. Based on the talents of the employees in performing certain work to be performed in the welding process, the welding foreman is able to divide the work to be performed so that the skills and abilities of his subordinate employees are used as fully as possible. In order to allocate tasks according to such principles for a specific period of time, the welding foreman must know the professional skills and abilities of welders, work plans developed in the system, data of technical drawings, operations and sequence of execution. The aim of the work is to find out how the assessment of the skills and abilities of each welder affects the production intensity. The benefits of the proposed welding organization are assessed by comparing the times in which different welders perform a single task.

In the test task, the welding speed is determined after the time of forming the joints, after the time spent for welding, its part in the operative time is determined. The operating time includes the jointing time $M H 1$, the welding time $M H 2$ and the basic time $M N$. The qualification of the welder and the quality of the seam can be judged from the test results.

\section{Materials and methods}

To find the skills and abilities of welders from the company's 50 welders, who weld with the MAG technology, 9 welders with different welding experience have been selected. Welders are assigned identification numbers from 1 to 9 . The task is to perform a specially designed test [9]. It is necessary to weld a T-joint from $4 \mathrm{~mm}$ thick, $210 \mathrm{~mm}$ long, $100 \mathrm{~mm}$ and $48 \mathrm{~mm}$ wide S235 LR steel plates. When welding 4 chess corner joints $30 \mathrm{~mm}$ long with a $4 \mathrm{~mm}$ catheter [z4 4x30 (30)] on one side of the vertical plate (side 1), the welder chooses the welding modes himself. When welding 3 analogue joints on the other side of the vertical plate - side 2, the welding mode is the same for all: current $195 \mathrm{~A}$, voltage $22.5 \mathrm{~V}$. The mutual position of the parts is fixed with a 90 degree magnet accessory and $2 \mathrm{~mm}$ thick spacers. Welding on side 1 is performed at 8 defined locations. Then 3 corner joints are welded with the specified welding modes on side 2 . In the next step, 4 corner seams are welded on side 1 of the welding joint, and the welding modes are chosen by the contractor based on the experience. This is followed by cleaning of welding debris and joint quality control. Fronius welding TPS 320i semi-automatic machines, shielding gas M21, welding wire G46 4 M G4Si, were used for welding. The welding process was monitored and recorded by video surveillance. DAHUA Technology video surveillance camera IPC-HFW1320S and Video LAN computer program were used.

The video records the date of each action and the time in hours: minutes: seconds. Direct measurements are summarized in seconds. The measurement results are summarized in an MS Excel table, which shows the time spent in minutes and percentages for each activity. The experimentally obtained use of the working time Tsum is calculated from the expression:

Tsum $=\Sigma M H+\Sigma M N+M Z 3+M E+M P$. The quality of the weld is determined by measuring the length 1 and height avid compliance of the welds with the drawing requirements. The seam formation speed $v$ is determined in mm.minutes ${ }^{-1}$ by dividing the total seam length $\Sigma l$ by the sum of seam formation times $\Sigma T w$. The time taken for welding is determined from the video surveillance results. The jointing $M H 1$ and the welding time $M H 2$ are recorded from the moment the electric arc ignites until the arc goes out. The operation time of $M N 1-M N 8$ is recorded with the actual start time of the operation and ends when the next operation starts. In order to assess the skills and abilities of each welder, data from the test results $M H 1$, weld time $M H 2$ and the preparation time $M N 5$ are used. The service life of each welder is calculated, and the arithmetic mean values determined. Then the ability of each welder to form a joint, perform welding and prepare to start welding, and the abilities with the average values for the group are compared. The result is coefficients that show the ability and skill of each welder to perform specific activities.

The plans of welding works developed in the system are intended for a certain period of time. The data of the technical drawings, the description of the operations and the sequence of execution for the works to be performed allows them to be assessed and distributed according to common features.

In the work all the tasks to be performed are divided into four groups: $K 001$ - simple welding connection, an auxiliary device is used in the welding process; $K 002$ - welding connection of complex construction from many parts, an auxiliary device is used in the welding process; $K 003$ - simple welding 
connection, no auxiliary device is used in the welding process; K004 - complex welding connection from few parts, an auxiliary device is used in the welding process. Complex welding joints are characterized by the joint length over $1000 \mathrm{~mm}$, number of tolerances more than 4 , mass over $4 \mathrm{~kg}$, use of welding accessories, welding joint grinding required, number of parts at least 5, connection volume at least $4 \mathrm{dm}^{3}$. For one typical part of each group, a video recording of welding time was recorded. The work is performed by a welder with average skills and abilities. Video recordings of $K 001$ type welded joints were made for 11 repeated measurements, the data were summarized in tables and mathematical data processing was performed. Production of $K 002$ product has been recorded 3 times. 2 repeat measurements were performed for the $K 003$ welded joint. The production process for $K 004$ has been taken 3 times. The summary of time use elements allows for analysis of the welding process.

The obtained data allow to model the production process of analogous products and to forecast the time required for their production. The welding process of $K 002$ type products is used for the model. They are characterized as complex welding joints and are made using a jig. The time required to manufacture the product is summed from the lead times of the individual working elements and can be expressed in general terms by formula 1 .

$$
T=[(M H 1+M H 2)+(M N 1+M N 2+M N 3+M N 4+M N 5+M N 6+M N 7)+M Z 3+M P] \cdot 1.0714 .
$$

Knowing the skills and abilities of each welder, it is possible to determine how long an individual will be able to weld a particular product. The modelling assumes that the welder's time spent in the MN5 test describes the welder's ability to perform other basic time-related activities. The qualification of a welder is assessed by the length of the welds welded in the test and the size of the catheter in $\mathrm{mm}$.

\section{Results and discussion}

Summarizing the test results on the ability of each welder to create a high-quality, drawingcompliant seam, to make adhesive joints that simultaneously mark the start and end points of the joints, to prepare for the welding process, the data are systematized in Table 1.

Table 1

Test results

\begin{tabular}{|c|c|c|c|c|c|c|c|c|c|c|}
\hline \multirow{2}{*}{ Parameter } & \multicolumn{9}{|c|}{ Welder code No. } & \multirow{2}{*}{ Average } \\
\hline & 1 & 2 & 3 & 4 & 5 & 6 & 7 & 8 & 9 & \\
\hline $\begin{array}{l}\text { Joint formation } \\
\text { time, } M H 1 \text {, min. }\end{array}$ & 0.76 & 0.87 & 0.63 & 1.10 & 0.68 & 0.72 & 0.78 & 0.95 & 0.73 & 0.80 \\
\hline $\begin{array}{l}\text { Catch welding } \\
\text { time, } M H 2, \text { min. }\end{array}$ & 0.45 & 1.02 & 0.30 & 0.63 & 0.32 & 0.32 & 0.80 & 0.53 & 1.63 & 0.67 \\
\hline $\begin{array}{l}\text { Preparation time, } \\
M N 5 \text {, min. }\end{array}$ & 1.32 & 1.85 & 1.33 & 1.27 & 1.55 & 2.55 & 3.08 & 2.28 & 1.13 & $\begin{array}{c}1.66- \\
\text { without } 7\end{array}$ \\
\hline $\begin{array}{l}M H 1+M H 2+M \\
N 5, \text { min. }\end{array}$ & 2.53 & 3.74 & 2.26 & 3.00 & 2.55 & 3.60 & 4.66 & 3.76 & 3.47 & 3.29 \\
\hline$D=\Sigma M H / M N 5$ & 0.92 & 1.02 & 0.70 & 1.36 & 0.65 & 0.41 & 0.51 & 0.65 & 2.09 & 0.92 \\
\hline $\begin{array}{l}\text { Total joint length, } \\
\text { mm }\end{array}$ & 242 & 264 & 241 & 240 & 232 & 244 & 223 & 244 & 237 & 241 \\
\hline $\begin{array}{l}\text { Average height of } \\
\text { joint, } \mathrm{mm}\end{array}$ & 3.84 & 3.68 & 3.27 & 4.46 & 3.91 & 3.61 & 4.19 & 3.72 & 3.70 & $3.82(4)$ \\
\hline $\begin{array}{l}\text { Speed of joint } \\
\text { formation, } v \\
\mathrm{~mm} \cdot \mathrm{min}^{-1}\end{array}$ & 318.4 & 303.4 & 382.5 & 218.2 & 341.2 & 338.9 & 285.9 & 256.8 & 324.7 & 307.5 \\
\hline $\begin{array}{l}\text { Volume of } \\
\text { melting metals, } \\
\mathrm{mm}^{3}\end{array}$ & 464.6 & 486.8 & 394.0 & 535.2 & 453.6 & 440.4 & 467.2 & 453.8 & 438.5 & $\begin{array}{l}420 \text { (after } \\
\text { drawing) }\end{array}$ \\
\hline $\begin{array}{l}\text { Length of service, } \\
\text { year }\end{array}$ & 5 & 4 & 8 & 8 & 2 & 2.5 & 1 & 2 & 5.5 & 4.2 \\
\hline
\end{tabular}

The test results show that the skills of welders to form a seam, to make connections with welding, to prepare for work are different and they do not always depend on the length of service of the welder. 
It can be seen that welder No.3 takes about twice as much time to complete the test task than welder No.7. The seam formation speed for welder No. 3 is 1.75 times higher than for welder No.4. Preparation time for welder No.7 is 2.7 times longer than for welder No.9. Coefficients shall be introduced to assess differences in the performance of the test elements. They show the skills and abilities of a particular welder compared to the group average:

$$
\text { K1 = MH1i/MH1aver.; } K 2=\text { MH2i/MH2aver.; } K 3=M N 5 i / M N 5 \text { aver., }
$$

where $i=1 \ldots 9$.

Table 2

Welder skills and ability coefficients

\begin{tabular}{|c|c|c|c|c|c|c|c|c|c|}
\hline \multirow{2}{*}{ Coefficients } & \multicolumn{9}{|c|}{ Welder code No. } \\
\cline { 2 - 10 } & 1 & 2 & 3 & 4 & 5 & 6 & 7 & 8 & 9 \\
\hline$K 1$ & 0.950 & 1.088 & 0.788 & 1.375 & 0.85 & 0.900 & 0.975 & 1.188 & 0.913 \\
\hline$K 2$ & 0.672 & 1.522 & 0.448 & 0.940 & 0.478 & 0.478 & 1.194 & 0.791 & 2.433 \\
\hline$K 3$ & 0.725 & 1.016 & 0.731 & 0.698 & 0.852 & 1.401 & 1.692 & 1.253 & 0.621 \\
\hline$K 1+K 2+K 3$ & 2.347 & 3.626 & 1.967 & 3.013 & 2.18 & 2.779 & 3.861 & 3.232 & 3.967 \\
\hline
\end{tabular}

Knowing the sum of the skill and ability ratios of each welder, we can determine how long a particular part can be produced. Applying the sum of the seam formation MH1 and the weld time MH2 to the sum of the preparation time $M N 5$, a coefficient $D$ is obtained. It shows the relationship between the time it takes a welder to form seams versus preparation time:

$$
D=(M H 1+M H 2) / M N 5 \text {. }
$$

Assessing the quality of the welders' work by the sum of the total weld lengths in relation to the drawing $(7 \times 30 \mathrm{~mm}=210 \mathrm{~mm})$ and the average size of the joint $-4 \mathrm{~mm}$, it must be concluded that all welders have exceeded the joint length, but the average seam length has reached $4 \mathrm{~mm}$. In addition, the seams of welder No.4 are on average are $11.5 \%$ higher than specified. The seam volume is ideally the same: $(4 \times 4) / 2 \times 210=1680 \mathrm{~mm}^{3}$. The data of Table 1 show the volumes of seams created by each welder. For welder No.3, the volume of the weld alone is $1288 \mathrm{~mm}^{3}$ less than ideal. Comparing the seam size, skill and ability coefficients, we conclude that the best indicators are for welders No.5 and No.1.

From analyses of the time elements of manufacturing standard parts, the information in [9] is used. The experimental data and their distribution are determined from the results obtained in the production of part $K 001$ in 10 video recordings. It is a simple welding joint that uses an accessory. Product weight is $1.93 \mathrm{~kg}$; volume $-3.60 \mathrm{dm}^{3} ; 3$ tolerances; the total length of the welds is $100 \mathrm{~mm}$; number of parts 3 . For each consumption element, the average values and standard deviation at $95 \%$ data reliability were calculated using the MS Excel program function "Descriptive statistics". The data are summarized in Table 3.

Table 3

K001 average values of working time of parts

\begin{tabular}{|c|c|c|}
\hline $\begin{array}{c}\text { Designation of time use } \\
\text { elements }\end{array}$ & Time spent, min & Time spent, \% \\
\hline$M H 1$ & $0.24 \pm 0.02$ & 25 \\
\hline$M H 2$ & $0.10 \pm 0.01$ & 10.5 \\
\hline$M N 1$ & $0.11 \pm 0.02$ & 11.25 \\
\hline$M N 2$ & $0.19 \pm 0.04$ & 19.5 \\
\hline$M N 3$ & $0.21 \pm 0.04$ & 22.25 \\
\hline$M N 4$ & $0.05 \pm 0.04$ & 5.25 \\
\hline$M Z 3$ & $0.06 \pm 0.03$ & 6.25 \\
\hline
\end{tabular}

Total time is 0.95 min over $100 \%$.

Based on the experimental data and expression (1) summarized in Table 4, a formula for the model of the time spent (3) is developed to produce the part K002:

$$
T K 002=[(M H 1+M H 2)+(M N 1+M N 2+M N 3+M N 4+M N 5] x 1.07 .
$$


A multiplier of 1.07 takes into account the regulated rest period [10]. Table 5 has been created to summarize the parameters required for the model: $M N=\Sigma(M N 1+M N 2+M N 3+M N 4+M N 5)$.

The calculations do not take into account the time wasted, the time of leaving the employee for a long time, the performance of activities that do not need to be performed according to the work plan, as well as the time of slag cleaning and related manipulations.

The data used for the production of welded joints $K 002, K 003$ and $K 004$ by analogous technology are summarized in Table 4.

Table 4

Elements used in manufacture of welded joints K001, K002, K003 and K004

\begin{tabular}{|l|c|c|c|c|}
\hline \multirow{2}{*}{\multicolumn{1}{|c|}{ Designation of time use elements }} & \multicolumn{4}{c|}{ Welded joints } \\
\cline { 2 - 5 } & $K 001$ & $K 002$ & $K 003$ & $K 004$ \\
\hline$M H 1$ - joint formation time, \% & 25 & 32.37 & 22.65 & 24.05 \\
\hline$M H 2$ - catch welding time, \% & 10.5 & 5.47 & 3.72 & 2.55 \\
\hline$M N 1$ - part transfer time, \% & 11.25 & 2.52 & 1.29 & 1.91 \\
\hline$M N 2$ - part fixation time, \% & 19.5 & 11.87 & 2.9 & 5.26 \\
\hline$M N 3$ - welding state change time, \% & 22.25 & 18.15 & 17.64 & 19.87 \\
\hline$M N 4$ - quality inspection time, \% & 5.25 & 1.49 & 7.77 & 1.51 \\
\hline$M N 5$ - preparation time, \% & - & 1.94 & 1.29 & 2.93 \\
\hline$M N 6$ - part processing time, \% & - & 0.23 & - & - \\
\hline$M N 7$ - aerosol application time, \% & - & 6.08 & 1.94 & - \\
\hline$M N 8$ - angle grinder application time, \% & - & 0.47 & - & - \\
\hline$M Z 3$ - slag cleaning time, \% & 6.25 & 8.62 & 35.28 & - \\
\hline$M E-$ time to relax, \% & - & 0.54 & - & 4.02 \\
\hline$M P-$ time for physiological needs, \% & - & 0.79 & - & - \\
\hline$M R-$ regulated break time, \% & - & 5.6 & - & - \\
\hline$M S-$ wasted time, \% & - & 4.2 & 4.05 & 37.89 \\
\hline Time of manufacturing of welding product, min & 0.95 & 47.66 & 4.94 & 17.84 \\
\hline Totally joint length, mm & 100 & 4196 & 322 & 1044 \\
\hline Number of parts in product & 3 & 13 & 2 & 5 \\
\hline Welded product mass, kg & 1.93 & 8.50 & 1.81 & 4.28 \\
\hline Number of measurements & 11 & 3 & 3 & 3 \\
\hline Number of tolerances & 3 & 5 & 5 & 4 \\
\hline
\end{tabular}

The data in the table show that the welding time is relatively short compared to the total basic welding time. The auxiliary time inevitably associated with welding is approximately equal to the time spent on welding for all products except $K 001$.

Table 5

Parameters to be used for modelling

\begin{tabular}{|l|c|c|c|c|}
\hline \multirow{2}{*}{ Designation of time use elements } & \multicolumn{4}{|c|}{ Welded production } \\
\cline { 2 - 5 } & $K 001$ & $K 002$ & $K 003$ & $K 004$ \\
\hline$M H$ - joint formation time, \% & 25 & 32.37 & 22.65 & 24.05 \\
\hline$M H 2$ - catch welding time, \% & 10.5 & 5.47 & 3.72 & 2.55 \\
\hline $\begin{array}{l}M N \text { - auxiliary time inevitably } \\
\text { associated with welding, \% }\end{array}$ & 58.25 & 36.67 & 32.84 & 31.48 \\
\hline Summary time for welding, \% & 93.5 & 74.54 & 59.2 & 58.1 \\
\hline
\end{tabular}

From the data in Table 5, using expression (2), we calculate the values of the coefficients $D$ for each of the standard products: $D_{K 001}=0.57 ; D_{K 002}=1.03 ; D_{K 003}=0.80 ; D_{K 004}=0.835$. The data show that the production of the investigated products consumes approximately the same time for welding and preparation, except for the product $K 001$. The expression: $T=\Sigma M H 1 K 1, M H 2, K 2, M N K 3$ is used to calculate the time $T$. Data are taken from Table 2 and Table 5. If the work were divided in such a way as to respect the abilities and skills of welders, and welders with lower coefficients $M H 1$ would weld joints with longer weld lengths, welders would weld alloys with lower $M N$ coefficients, which require 
more auxiliary time to produce. Welder No. 7 can be assigned to works where the auxiliary time $M N$ is less than the seam formation time $M H$. The calculations assume that $K 001$ and $K 003$ type parts with relatively shorter joint formation time will be made by welders with higher coefficients $K 1$ in Table 2 , respectively welders No. 1, 2, 4, 8, but $K 002$ and $K 004$ type parts will be made by welders No. 3, 5, 6, 9.

When modelled the course of welding work, the time wasted, the employee's long-term abandonment of work, the performance of activities that do not need to be performed according to the work plan, as well as the time of welding slag cleaning, are not taken into account in the calculations.

The production time $T_{K 001}$ of product $K 001$ for a welder with average skills and abilities is determined by: $T_{K 001}=M H 1+M H 2+M N=93.5 \%$. For each of the four welders from the first group and four welders from the second group the manufacturing time $T_{N o i}$ of products is determined by an analogous relationship.

Table 6

Projected manufacturing times of product

\begin{tabular}{|c|c|c|c|c|c|}
\hline \multirow{2}{*}{ Product } & \multicolumn{5}{|c|}{ Production time, \% } \\
\cline { 2 - 6 } & $T_{N o 1}$ & $T_{N o 2}$ & $T_{N o 4}$ & $T_{N o 8}$ & $\Sigma T_{N o} / 4$ \\
\hline$K 001$ & 73.1 & 102.4 & 85.0 & 110.3 & 92.7 \\
\hline$K 003$ & 47.8 & 63.8 & 57.6 & 70.7 & 60.0 \\
\hline- & $T_{N o 3}$ & $T_{N o 5}$ & $T_{N o 6}$ & $T_{N o 9}$ & $\Sigma T_{N o} / 4$ \\
\hline$K 002$ & 55.1 & 61.2 & 83.0 & 65.6 & 66.2 \\
\hline$K 004$ & 43.1 & 48.5 & 66.9 & 47.7 & 51.55 \\
\hline
\end{tabular}

The obtained results in Table 6 show that with the existing welding contingents No1, No2, No4, No8 the production intensity of part K001, dividing the work according to the abilities and skills shown in the welders' test, can be increased by about $1 \%$, the production intensity of part $K 003$ cannot be increased. The production intensity of part $K 002$ with the existing welding contingents No3, No5, No6, No9 can be increased by about $8 \%$ and part $K 004$ by about $6 \%$. By entrusting cleaning of welding slag to less skilled workers or machines, the welding intensity of part $K 002$ could be increased by about $18 \%$ and part $K 003$ by about $35 \%$.

\section{Conclusions}

1. When organizing welding work in series production, it is important to assess the professional skills and abilities of each welder in the performance of individual elements.

2. It was found that the work of a welder is characterized by the relationship between the time he needs to create the seams and the preparation time.

3. By modelling the welding process, it has been found that by properly organizing the production, the contingent of the welder work intensity can be increased by $8 \%$.

4. Welding slag treatment should be entrusted to less qualified personnel or machinery. By entrusting the cleaning of welding slag to less qualified personnel or machines, the welding intensity of a complex product could be increased by $18 \ldots 35 \%$.

\section{References}

[1] Lawrence, S. Work Measurement and Methods improvement. John Wiley \&Sons, Inc., 2000, 452 p.

[2] Menggelsone L. Labor standardization methodology. 2013, 58 p. (In Latvian)

[3] Mendoza J.D, Mula J., Bolarin F.C. Using systems dynamics to evaluate the tradeoff among supply chain aggregate production planning policies. Journal of Operations \& Production Management, 2014.34(8).

[4] Van Hootegem G., Huys R., Delarue A. The sustainability of teamwork under changing circumstances: The case of Volvo-Ghent. Journal of Operations \& Production Management, 2004. pp. 773-786.

[5] Baines T.S., Kay G., Adesola S., Higson M. Strategic positioning: An integrated decision process for manufacturers. Journal of Operations \& Production Management, 2005, pp. 180-201.

[6] C. Weidmann, L. Teuber: Konzeption und Einrichtung des Systemmonitorings mit den SAP Solution Manager. Galileo Press 2009. 
[7] REFA (2014) REFA - grundausbildung 2,0 Teil @ a ermittlung und anwendung von pocesstaten. Heistungsgradbeuerteilung, REFA group.

[8] Todd R.H., Allen D.K., AltingL. Manufacturing process reference guide. Industrial Press. 1994. $486 \mathrm{p}$.

[9] Elere K. MIG, MAG welding process time and cost rationing methotodology: Masters thesis. Jelgava: Latvia University of Agriculture, 2017. 83 p.

[10] MK regulations Nr.1528, from 2013.g.17.dec. 